\title{
Biomarkers of lipid peroxidation, airway inflammation and asthma
}

\author{
L.G. Wood*, P.G. Gibson*, M.L. Garg\#
}

Biomarkers of lipid peroxidation, airway inflammation and asthma. L.G. Wood, P.G. Gibson, M.L. Garg. (C)ERS Journals Ltd 2003.

ABSTRACT: Oxidative stress, specifically lipid peroxidation, is believed to contribute to the pathophysiology of asthma. This review highlights the pathways through which reactive oxygen species (ROS) may lead to lipid peroxidation. The potential of both the innate and acquired immune systems to activate inflammatory cells and release ROS that may overwhelm the host antioxidant defences and cause lipid peroxidation, accompanied by detrimental pathophysiological effects, are discussed.

Despite the evidence demonstrating the importance of lipid peroxidation, systematic characterisation of oxidative stress and antioxidant defences has not been undertaken, largely due to the lack of appropriate biomarkers. This review discusses the emergence of isoprostanes (specifically 8-iso-prostaglandin $\mathrm{F}_{2 \alpha}$ ) as reliable, in vivo markers of lipid peroxidation, which provides an appropriate tool for studying oxidative stress. Furthermore, the development of techniques to study induced sputum and breath condensate, derived directly from the airway surface, enables the site of oxidative damage to be closely assessed.

Evidence suggests that dietary changes that have occurred over recent years have increased susceptibility to lipid peroxidation, due to reduced antioxidant defences. To date, the limited number of long-term ( $>1$ week) supplementation trials have been promising. However, the development of techniques to study isoprostanes in airwaylining fluid pave the way for further studies investigating the potential for antioxidant supplements to be used as routine therapy in asthma.

Eur Respir J 2003; 21: 177-186.

*Hunter Medical Research Institute, Dept of Respiratory and Sleep Medicine, John Hunter Hospital, New Lambton Heights and ${ }^{\#}$ Hunter Medical Research Institute, University of Newcastle, Callaghan, Australia.

Correspondence: P. Gibson, Dept of Respiratory and Sleep Medicine, John Hunter Hospital, Locked Bag 1, Hunter Mail Centre, New South Wales, 2310, Australia.

Fax: 61249213469

E-mail: mdpgg@mail.newcastle.edu.au

Keywords: Antioxidants

asthma

isoprostanes

lipid peroxidation

oxidative stress

Received: September 272001

Accepted after revision: August 72002
Asthma is a chronic inflammatory disorder of the airways, involving variable airflow obstruction and increased airway responsiveness to a variety of stimuli [1]. The airway mucosal inflammatory response in asthma is characterised by increased vascular permeability with oedema of airway walls, mucus hypersecretion with small airway plugging and infiltration by inflammatory cells, typically eosinophils. Asthma prevalence has increased dramatically in recent years [2]. Epidemiological evidence suggests that changes in diet, in particular reduced antioxidant intake, have contributed to increases in asthma prevalence and severity and raises the possibility that dietary interventions may improve asthma [3]. While oxidant damage is an established consequence of inflammation, the role of antioxidants and reactive oxygen species (ROS) in asthmatic airway inflammation is ill-defined and needs further exploration. Progress in this area has been limited by the lack of sensitive and specific biomarkers of oxidative stress. Isoprostanes are a group of recently discovered lipid peroxidation products that may contribute to many of the pathophysiological changes seen in asthma. This paper reviews recent data on the effects of isoprostanes in asthma and their place as biomarkers of oxidative stress.

\section{Oxidative stress in asthma}

Oxidative stress describes the damage that occurs when ROS overwhelm the antioxidant defences of the host. Oxidative stress may play an important role in the pathophysiology of asthma [1,4] and may be a final common pathway leading to tissue damage. Figure 1 is a simplified description of how exposure to a variety of different substances such as allergens, gaseous pollutants, chemicals, drugs, bacteria and viruses [5] leads to the recruitment and activation of inflammatory cells in asthmatic airways, including mast cells, eosinophils, neutrophils, lymphocytes, macrophages and platelets. As indicated in figure 1, allergen-specific reactions involving the acquired immune system are characterised by the production of interleukin (IL)-5 and the subsequent recruitment and activation of eosinophils. In contrast, stimuli that act via the innate immune system lead to the production of IL-8 and the subsequent recruitment and activation of neutrophils. However, both of these pathways lead to the production of ROS, primarily due to the respiratory burst of activated inflammatory cells.

Activated inflammatory cells respond with a "respiratory burst", which involves the uptake of oxygen 


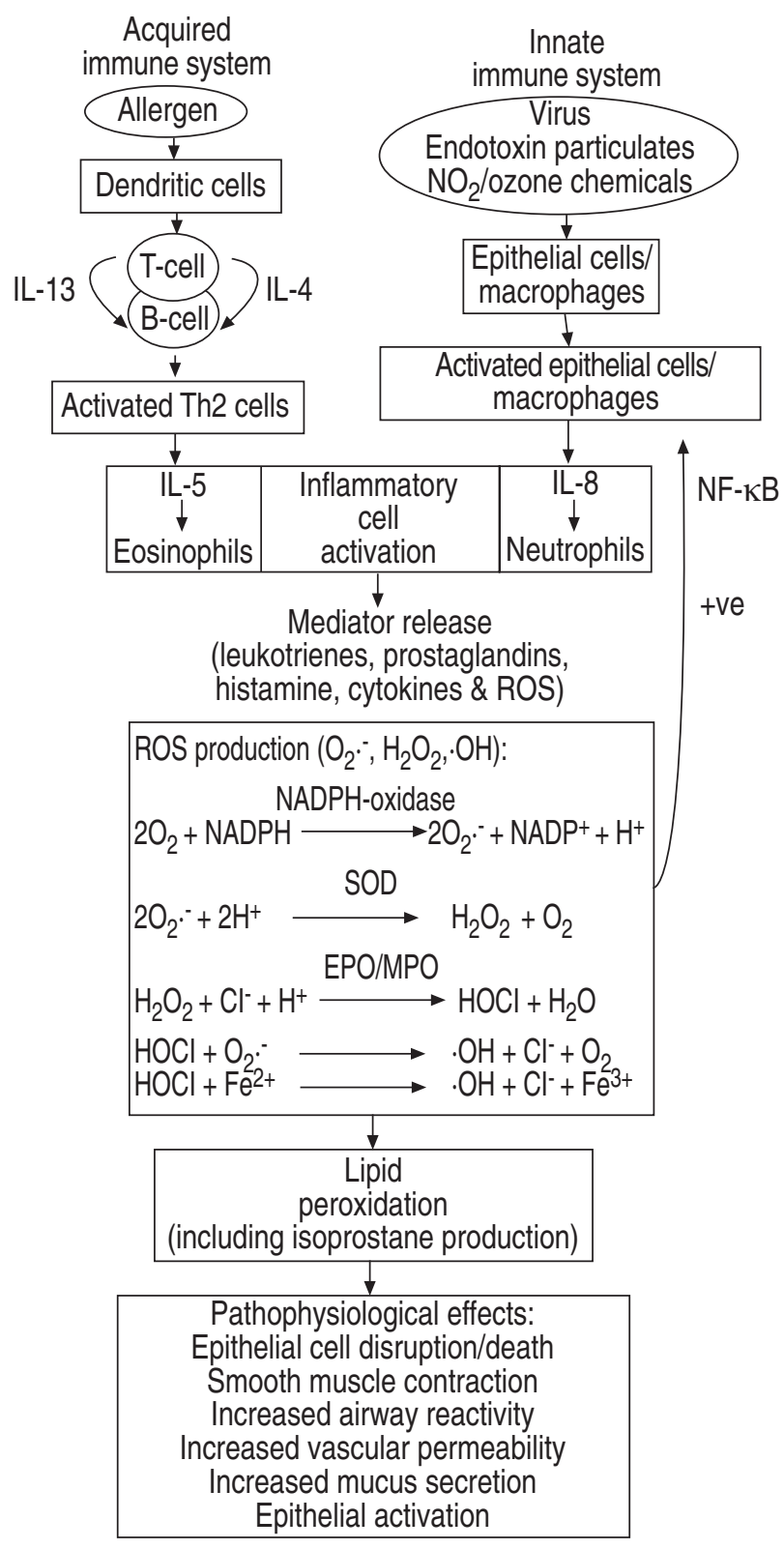

Fig. 1.-Mechanisms leading to lipid peroxidation in asthma. IL: interleukin; Th2: T-helper type-2 cells; $\mathrm{NO}_{2}$ : nitrogen dioxide; ROS: reactive oxygen species; $\mathrm{O}_{2}{ }^{--}$: superoxide; $\mathrm{H}_{2} \mathrm{O}_{2}$ : hydrogen peroxide; -OH: hydroxyl radical; NADPH: reduced nicotinamide-adenine dinucleotide phosphate; NADP: nicotinamide-adenine dinucleotide phosphate; SOD: superoxide dismutase; EPO: eosinophil peroxidase; MPO: myeloperoxidase; NF: nuclear transcription factor.

and subsequent release of ROS into surrounding cells. During the respiratory burst, a reduced nicotinamideadenine dinucleotide phosphate-dependent superoxidegenerating system is activated and releases superoxide $\left(\mathrm{O}_{2} \cdot^{-}\right)$into the cell. A dismutation reaction, catalysed by superoxide dismutase (SOD) then results in the production of hydrogen peroxide $\left(\mathrm{H}_{2} \mathrm{O}_{2}\right)$, which, in the presence of halide ions (i.e. $\mathrm{I}^{-}, \mathrm{Cl}^{-}, \mathrm{Br}^{-}$), will react to form a hypohalous acid (e.g. $\mathrm{HOCl} / \mathrm{HOBr})$. In eosinophils, this reaction is catalysed by eosinophil peroxidase (EPO). In neutrophils, this reaction is catalysed by myeloperoxidase. $\mathrm{HOCl} / \mathrm{HOBr}$ may then react with $\mathrm{O}_{2} \cdot{ }^{-}$or $\mathrm{Fe}^{2+}$ to produce another strong oxidant, probably the hydroxyl radical $(\cdot \mathrm{OH})$. Thus, during this "respiratory burst", the inflammatory cells have released high concentrations of $\mathrm{O}_{2}{ }^{-}, \cdot \mathrm{OH}, \mathrm{HOCl} /$ $\mathrm{HOBr}$ and $\mathrm{H}_{2} \mathrm{O}_{2}$ that may leak into surrounding cells resulting in increased quantities of free radicals in airway tissues. Furthermore, the inflammatory cells of asthmatics have an increased capability to generate free radicals compared to controls, which further contributes to high concentrations of ROS [6-8]. Excess reactive nitrogen species (RNS) may also be produced by asthmatics. Cytokines may stimulate increased production of nitrosyl (NO*) [9] which reacts with $\mathrm{O}_{2} \cdot^{-}$to form peroxynitrite, a cytotoxic species that has many damaging effects, including lipid oxidation [10]. NO can also be converted to nitrite, which can oxidise proteins. This may be through nitration of tyrosine, in a reaction catalysed by EPO [11]. Elevated nitrotyrosine levels have been observed in asthmatics [12]. Thus, the excess quantities of ROS and RNS that are produced by asthmatics may overcome the host antioxidant defences and cause oxidative stress.

\section{Consequences of oxidative stress in asthma}

Oxidative stress can have many detrimental effects on airway function, including airway smooth muscle contraction [13], induction of airway hyperresponsiveness [14, 15], mucus hypersecretion [16, 17], epithelial shedding [18] and vascular exudation [19, 20]. Furthermore, ROS can induce cytokine and chemokine production through induction of the oxidative stress-sensitive transcription of nuclear factor- $\kappa \mathrm{B}$ in bronchial epithelial cells [21].

Peroxidation of membrane lipids leads to the production of isoprostanes, a recently discovered series of bioactive prostaglandin $(\mathrm{PG}) \mathrm{F}_{2}$-like compounds. Isoprostanes are produced independently of the cyclooxygenase enzymes via the peroxidation of arachidonic acid, catalysed by free radicals. This pathway has the potential to form 64 isomeric structures, of which 8-iso-PGF $2 \alpha$ is the most well characterised. Isoprostanes have significant biological activity (table 1). Evidence suggests that 8-iso- $\mathrm{PGF}_{2 \alpha}$ may act in part through the vascular thromboxane $\mathrm{A}_{2} / \mathrm{PGH}_{2}$ (TP) receptor [31]. However, it has been suggested that 8 -iso- $\mathrm{PGF}_{2 \alpha}$ may also act through a novel receptor, closely related to but distinct from the TP receptor, with a high specificity for 8 -iso- $\mathrm{PGF}_{2 \alpha}$ [32]. 8-iso-PGF $2 \alpha$ has been found to be a potent constrictor of smooth muscle. This effect has been observed in vitro in human and guinea pig airways [22] as well as in cultured rat aortic smooth muscle [23]. 8 -iso- $\mathrm{PGF}_{2 \alpha}$ has also been shown to elicit airway hyperresponsiveness in isolated perfused mouse lungs [24], and cause airway obstruction and airway plasma exudation in guinea pigs in vivo [25]. Another isoprostane isomer, 8-iso-PGE 2 , has been shown to produce physiological responses similar to 8 -iso- $\mathrm{PGF}_{2 \alpha}$, but at reduced potency [33]. These experiments invite speculation about the contribution of isoprostanes to the airway narrowing that is characteristic of asthma. 
Table 1. - Effects of isoprostanes (8-iso-prostaglandin $(P G) F_{2 \alpha}$ ) in asthma

\begin{tabular}{|c|c|}
\hline In vitro/animal models & Human studies \\
\hline Smooth muscle constriction $[22,23]$ & $\uparrow$ 8-iso-PGF ${ }_{2 \alpha}$ in asthma (plasma [28]; breath condensate [29]) \\
\hline $\begin{array}{l}\text { Alrway nyperreponsivene } \\
\text { Airway obstruction [25] }\end{array}$ & 8-iso-PGF \\
\hline Plasma exudation $[25]$ & 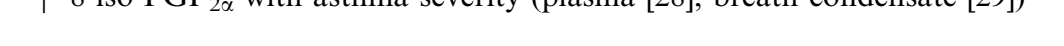 \\
\hline Vascular constriction $[26,27]$ & $\uparrow 8$-iso-PGF $2 \alpha$ with allergen challenge (urine and bronchoalveolar lavage [30]) \\
\hline
\end{tabular}

While the situation in humans in vivo may be different, the full impact of elevated isoprostane levels on pulmonary function remains to be established, and in addition to being a reliable marker of lipid peroxidation, isoprostanes may prove to have an important biological role in the pathophysiology of asthma.

\section{Evidence relating lipid peroxidation and asthma}

Direct measurement of oxidants is difficult since they are highly reactive, short-lived species. Thus, oxidative stress is often measured by observing the damage inflicted by oxygen radicals upon various biomolecules, such as lipids, proteins or deoxyribonucleic acid. Aspects of the antioxidant defence system are also often examined as an indirect marker of oxidative stress. Lipid peroxidation is of particular significance in asthma (fig. 1). Table 2 summarises some of the studies that have investigated lipid peroxidation and antioxidant defences in asthma.

Recently published data from the authors' laboratory [28] demonstrated elevated lipid peroxidation in asthma, as measured by 8 -iso- $\mathrm{PGF}_{2 \alpha}$ (fig. 2). There is overlap between the healthy and asthmatic groups, due to the least severe asthmatics (infrequent episodic) demonstrating median 8 -iso- $\mathrm{PGF}_{2 \alpha}$ concentrations similar to normal values, while the persistent asthmatics demonstrated median 8 -iso- $\mathrm{PGF}_{2 \alpha}$ concentrations 3-4 times the normal group [28]. This data is supported by other researchers [29] who have observed elevated 8 -iso- $\mathrm{PGF}_{2 \alpha}$ in breath condensate of asthmatics. Further evidence that allergen-induced asthma involves ROS and lipid peroxidation is the increase in urinary and bronchoalveolar lavage (BAL) fluid isoprostanes following an allergen challenge [30]. The increased isoprostane concentration in BAL fluid $24 \mathrm{~h}$ after the challenge provides direct evidence that isoprostanes are produced in airway tissue and may contribute to the physical effects observed during the late response.

Other lipid peroxidation products have also been measured in asthma. Thiobarbituric acid-reactive substances (TBARS) measure the concentration of malondialdehyde (MDA), an end product of the oxidation and decomposition of polyunsaturated fatty acids containing three or more double bonds. Elevated MDA levels have been observed in both plasma [34-37] and breath condensate in asthmatics [38]. Ethane is produced following lipid peroxidation of n-3 fatty acids and elevated ethane levels have been reported in breath condensate of asthmatics [39]. Exhaled pentane levels, produced following peroxidation of n- 6 fatty acids, were not different to controls [40].

Antioxidant deficiencies have been frequently reported in asthmatics. The data is inconsistent, possibly due to variations in disease severity, diet, analytical techniques and body fluids being measured. However, overall, an antioxidant deficiency is indicated. Reports of nonenzymatic antioxidant deficiency include vitamin C (plasma/serum [35, 41, 42], whole blood [36] and BAL fluid [43]), vitamin E (BAL fluid [43], bronchial wash [43], plasma/serum [35, 36] and erythrocytes [44]) and $\beta$-carotene (serum [35]). Glutathione (GSH) is a key antioxidant in the lining fluid of the respiratory tract. Disturbed GSH status is reported in asthma, with total [45] and oxidised [43] GSH being elevated in BAL fluid and reduced GSH being elevated in erythrocytes [42]. This suggests that GSH synthesis and/or transport has increased in response to the presence of excess oxidants and has subsequently been oxidised as it performs its antioxidant role. A compensatory but probably inadequate increase in GSH has been reported in other conditions of oxidative stress [64, 65].

Reports on enzymatic antioxidant status in asthma are also inconsistent. SOD and glutathione peroxidase (GSHPx) form an important part of the antioxidant defence system. SOD catalyses the dismutation of $\mathrm{O}_{2} .^{-}$ into oxygen and hydroperoxide, which is then acted upon by GSHPx to form water. SOD activity has been reported to be increased [46], decreased [36, 47-51] or unchanged [28, 44, 45, 52, 53] in asthmatics compared with controls. $\mathrm{Zn}$, a cofactor of SOD, has also been reported to be decreased [28, 54] or unchanged [55]. Similarly, GSHPx activity has been reported to be decreased [36, 44, 53, 56-61] or unchanged [28, 47-49, $51,52,57,60,62]$ in asthmatics, with Se, a cofactor of GSHPx, being decreased [28, 57, 60-62] or unchanged $[49,57,62]$. Catalase, another antioxidant enzyme, has also been reported to have low activity [36, 52] or unchanged [44, 47, 48, 51]. While the data are difficult to compare due to differences in the disease severity, blood components and body fluids being measured, it is clear that overall, the status of the antioxidant enzymes and their cofactors is often altered in asthma, indicating a disturbed oxidant/antioxidant balance.

There are a number of reports on oxidative stress in asthma, involving other markers such as direct measurement of ROS or protein oxidation, rather than lipid peroxidation. Some examples include elevated breath condensate levels of carbon monoxide [66], nitric oxide [12, 39, 44, 66, 67], nitrotyrosine [12] and $\mathrm{H}_{2} \mathrm{O}_{2}[38,66]$. These data provide further evidence of oxidative stress in asthma. 
Table 2. - Markers of oxidative stress in asthma

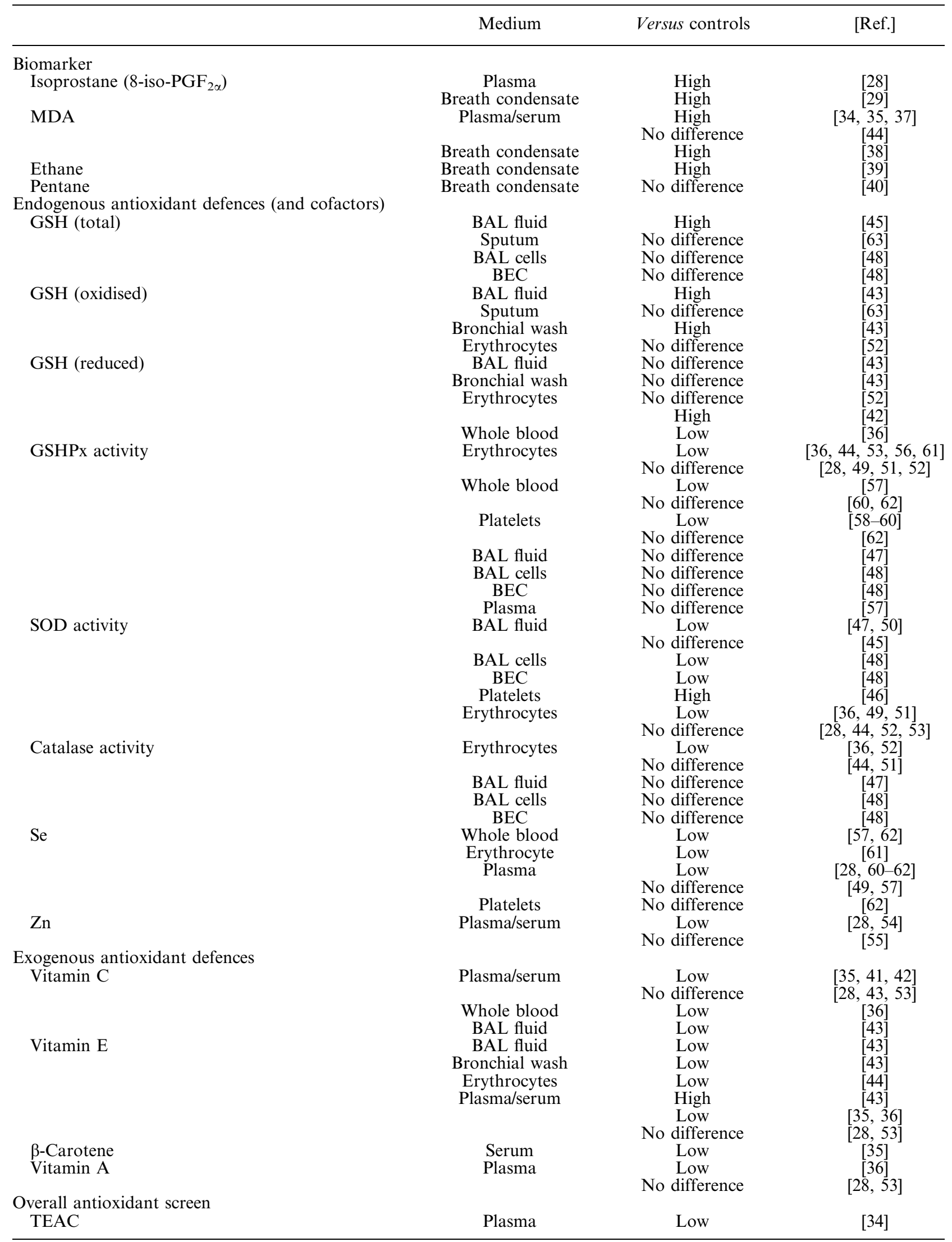

MDA: malondialdehyde; GSH: glutathione; BAL: bronchoalveolar lavage; BEC: bronchial epithelial cells; GSHPx: glutathione peroxidase; SOD: superoxide dismutase; TEAC: Trolox equivalent antioxidant capacity. 


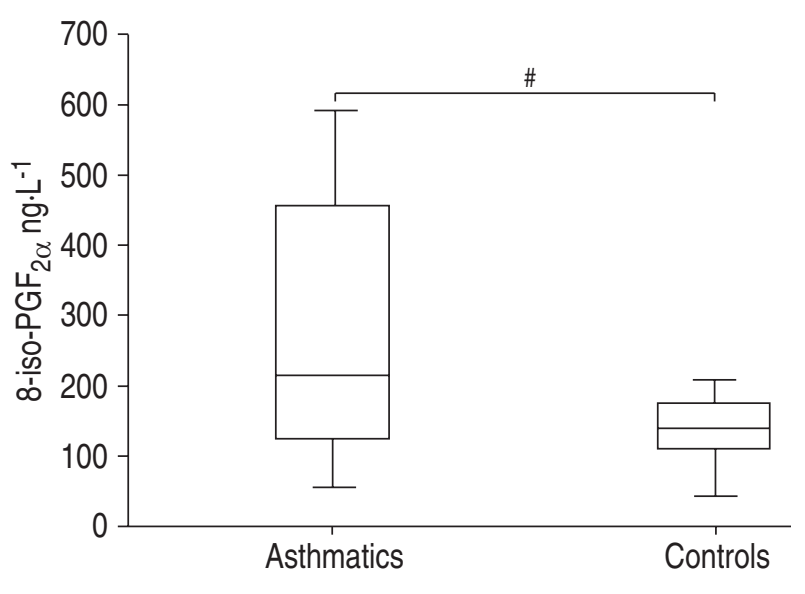

Fig. 2. - Plasma 8-iso-prostaglandin $(\mathrm{PG}) \mathrm{F}_{2 \alpha}$ concentrations in asthmatics $(n=15)$ versus controls $(n=15)$. Plot shows median (horizontal bar through box) and interquartile range [28]. ${ }^{\#}$ : $\mathrm{p}=0.042$.

\section{Lipid peroxidation is related to asthma severity}

The data previously published by the current authors also indicated that asthma severity is related to the extent of lipid peroxidation [28], with a positive association between 8-iso- $\mathrm{PGF}_{2 \alpha}$ concentrations and disease severity. A similar trend was recently reported by MonTuschi et al. [29] who also reported that 8-iso$\mathrm{PGF}_{2 \alpha}$ levels increased in breath condensate as asthma severity increased. A recent study by PAREDI et al. [39] also provides evidence that lipid peroxidation is related to asthma severity. This study demonstrated that concentrations of exhaled ethane were increased in patients with more severe bronchoconstriction (forced expiratory volume in one second $(\mathrm{FEV} 1)<60 \%$ ), compared with less-constricted patients $(\mathrm{FEV} 1>60 \%)$. These relationships between markers of oxidative stress (in particular 8-iso-PGF ${ }_{2 \alpha}$ ) and disease severity suggest that such tests may indicate the clinical status of asthma patients. Further work is needed to determine reference ranges for oxidative stress biomarkers (including isoprostanes) in asthmatics of various disease severities and clinical status if they are to become a useful clinical tool.

\section{Isoprostanes as a biomarker of lipid peroxidation in asthma}

Elevated 8-iso- $\mathrm{PGF}_{2 \alpha}$ concentrations have been observed in a variety of respiratory diseases, including cystic fibrosis [68, 69], interstitial lung diseases [70], chronic obstructive pulmonary disease [71, 72] and asthma [28, 29]. It is likely that the mechanisms leading to oxidative stress vary according to the disease, thus this review article focuses on asthma. The discovery of isoprostanes has generated much interest, as they provide a reliable index of oxidative stress in vivo. Isoprostanes are structurally stable, are produced in vivo and are present in relatively high concentrations [73]. Thus, they overcome many of the methodological problems associated with other markers. Most methods previously available to assess oxidative stress in vivo suffer from a lack of specificity and/or sensitivity and are unreliable. Detectable levels of $\mathrm{F}_{2}$-isoprostanes can be found in all normal animal and human biological fluids (including plasma, urine, bile, gastric juice, synovial fluid and cerebrospinal fluid), and esterified in normal animal tissues. Levels of $\mathrm{F}_{2}$-isoprostanes detected exceed those of cyclooxygenasederived prostanoids by one to two orders of magnitude [74]. Indeed, as a marker of oxidative stress, 8 -iso-PGF $2 \alpha$ determination of carbon tetrachloride $\left(\mathrm{CCl}_{4}\right)$-induced lipid peroxidation has been shown to be 20 times more sensitive than measurement of TBARS [73].

In models of oxidant injury, levels of $\mathrm{F}_{2}$-isoprostanes free in the circulation and esterified to tissue phospholipids are dramatically increased. For example, excretion of $\mathrm{F}_{2}$-isoprostanes in the bile of normal rats after administration of $\mathrm{CCl}_{4}$ was observed to increase in a dose-dependent manner [75]. Hepatotoxic doses of $\mathrm{CCl}_{4}$ have also caused hepatic lipid-esterified $\mathrm{F}_{2-}$ isoprostanes to increase up to 200 -fold within $1 \mathrm{~h}$ [76]. AwAD et al. [76] also studied specific halothaneinduced lipid peroxidation in rats. A four-fold increase in plasma $\mathrm{F}_{2}$-isoprostanes and an 11-fold increase in liver $\mathrm{F}_{2}$-isoprostanes was observed.

Isoprostanes are stable when stored at $-70^{\circ} \mathrm{C}$ for up to 6 months [77]. The most common methods of quantifying isoprostanes are gas chromatographymass spectrometry (GC-MS) and enzyme immunoassay (EIA). EIA is available in kit form and thus is a very quick, simple and cost-effective technique. The values of total 8-iso- $\mathrm{PGF}_{2 \alpha}$ observed in the authors' laboratory in normal plasma using the EIA method $[28,68]$ were similar to those obtained by Morrow et al. [78] using GC-MS. Batch-to-batch variability is minimised using standard curves with each assay plate. The major disadvantage of EIA kits is that the kits available at present only contain antibodies specific for the 8-iso- $\mathrm{PGF}_{2 \alpha}$ isomer. GC-MS has the advantage of being able to detect the multiple isomeric forms of isoprostanes. However, the equipment is costly and not widely available and the sample preparation protocols are time and labour intensive [33]. Thus, the use of specific immunoassays have expanded research in this area, with several recent studies reportedly using the EIA methodology [28, 29, 70, 71, 79, 80].

The reliability of isoprostanes as in vivo markers of lipid peroxidation makes them an extremely valuable tool for defining the potential of antioxidant agents [81]. There are numerous opportunities for trials to examine the effects of antioxidants in preventing or ameliorating the pathology of diseases in which oxidative stress is implicated. Measurement of isoprostanes can provide information regarding which doses or combinations of antioxidants are maximally effective. Several studies have demonstrated that isoprostane levels can be suppressed using antioxidants. Administration of high doses of an antioxidant combination (including vitamin $\mathrm{C}, \mathrm{E}$ and $\beta$-carotene) in humans for 2 weeks reduced formation of isoprostanes by $25-55 \%$ [81]. Similarly, a trial in which subjects received high doses of vitamin E for 2 weeks reduced isoprostane levels by $37 \%$ [81]. Another trial 
including patients with hepatorenal syndrome revealed that infusion with SOD in three patients resulted in a $50 \%$ decrease in circulation levels of $\mathrm{F}_{2}$-isoprostanes, only 30-60 min after initiating the infusion [73]. Furthermore, $\mathrm{F}_{2}$-isoprostane levels are increased in animals deficient in natural antioxidants, even without additional oxidant stress [73]. The isoprostanes have emerged as an effective method of quantifying the potential of antioxidants to inhibit lipid peroxidation.

Evidence has been presented to show that oxidised dietary fat does not interfere with isoprostane measurement. In a study by Gopaul et al. [82], a high-fat, fast-food meal did not contribute to the short-term postprandial concentrations of plasma 8-iso- $\mathrm{PGF}_{2 \alpha}$. This is probably due to a dilution effect, as the quantity of 8-iso-PGF $2 \alpha$ obtained from a high-fat meal when diluted into the circulating blood volume is small compared with endogenous levels. This data is supported by others [74, 83], who have also shown that urinary concentrations of 8 -iso- $\mathrm{PGF}_{2 \alpha}$ were unlikely to be compromised by diet.

There has been some suggestion that 8 -iso-PGF $2 \alpha$ may also be produced enzymatically by cyclooxygenase activity by some cells and tissues in vitro [84], which raises questions regarding the validity of isoprostanes as a marker of oxidative stress. Monocytes and platelets have shown the ability to synthesise 8iso-PGF $\mathrm{PG}_{2 \alpha}$ via both cyclooxygenase and free radicalcatalysed mechanisms in vitro [85]. However, the quantities produced enzymatically appear to be trivial compared with the overall 8 -iso- $\mathrm{PGF}_{2 \alpha}$ synthesis [86]. Furthermore, enzymatic production does not appear to occur in humans in vivo [72].

\section{Other biomarkers of lipid peroxidation}

Although biomarkers such as concentrations of MDA, breath alkanes, hydroperoxides and others are satisfactory in many circumstances, they have met criticism by a number of investigators, particularly when examining oxidative stress in vivo [87, 88]. These tests have limited specificity and/or sensitivity for oxidative stress or may be unreliable when applying the techniques to human subjects [87].

\section{Thiobarbituric acid-reactive substance}

MDA concentrations are often determined using the thiobarbituric acid (TBA) assay. MDA is an end product of the oxidation and decomposition of polyunsaturated fatty acids containing three or more double bonds. MDA is derived from TBA to form the MDA-TBA adduct. This adduct is most commonly quantified using a spectrophotometric assay [88]. There have been concerns about the specificity and validity of the TBARS assay [87, 88]. The reasons for concern include possible interference with haemoglobin or biliverdin present in the sample, the heating condition during the assay, the presence of iron in the reagents used for analysis, rapid metabolism of MDA and the fact that MDA represents $<1 \%$ of lipid peroxides [88]. Thus, it is not recommended to be used as a sole index of lipid peroxidation [89]. Some investigators are now measuring MDA directly, by using high-performance liquid chromatography (HPLC) to separate MDA from other interfering chromagens, thus improving specificity [90]. However, this approach does not overcome all the limitations of the MDA method.

\section{Lipid hydroperoxides}

Primary peroxidation products of lipids can be detected in plasma using HPLC or GC-MS. The instability of lipid hydroperoxides can make measurements difficult, as they are readily broken down into alkenes and aldehydes [88].

\section{Hydrocarbon breath test}

This noninvasive technique involves measuring pentane exhalation as the end product of (n-6) fatty acid peroxidation and ethane exhalation as the end product of (n-3) fatty acid peroxidation [88]. The test may be misleading, as hydrocarbon gas production depends on the presence of metal ions to decompose lipid peroxides. If such ions are only available in limited amounts, this index may be inaccurate [91]. Other problems include contamination of the atmosphere by these gases, the metabolism of pentane in the liver by cytochrome P450 [88, 91] and the concentration of oxygen in vivo, which affects gas production [91].

\section{Oxidative resistance of low-density lipoproteins}

The resistance of low density lipoproteins (LDL) to induced oxidative stress has been established as a model for studying the protection of polyunsaturated fatty acids by antioxidants in vivo [92]. When isolated LDL is exposed to $\mathrm{Cu}^{2+}$ as a pro-oxidant under standardised conditions, the lag time preceding the onset of lipid peroxidation formation indicates resistance of LDL to oxidative stress. This test is also subject to criticism as it cannot be known for certain whether the in vitro situation accurately reflects in vivo events.

\section{Antibodies against oxidised low-density lipoproteins}

Measurement of auto-antibodies directed against oxidative modifications of LDL is a recently developed technique that provides an in vivo marker of lipid peroxidation [93]. Enzyme-linked immunosorbent assays are available in kit form, providing a quick and simple methodology. However, further understanding of the mechanisms leading to oxidative modification of LDL is necessary, as it has been suggested that such modifications may occur independently of lipid peroxidation [94]. 


\section{Antioxidant concentrations}

Various biological tissues and fluids contain a range of antioxidants to protect against oxidative damage. For example, human blood contains small molecular antioxidants such as vitamin $\mathrm{E}, \mathrm{C}$ and $\beta$-carotene, as well as enzymatic antioxidants such as SOD, GSHPx and catalase. Important antioxidants in the respiratory tract lining fluid include reduced $\mathrm{GSH}$, mucin, uric acid, vitamin $\mathrm{C}$ and albumin [95]. Antioxidants are consumed in times of oxidative stress, thus measurement of these is an indirect marker of the degree of oxidative stress in a system. However, such data must be interpreted with caution, as antioxidant deficiencies may be due to factors other than increased utilisation.

\section{Trapping antioxidant potential/Trolox equivalent antioxidant capacity assays}

The total radical trapping antioxidant potential (TRAP) and Trolox equivalent antioxidant capacity (TEAC) are assays designed to describe total capacity to withstand free-radical stress [96]. The TRAP assay measures the ability of plasma to buffer a sample of linoleic acid against peroxidation using a heat-labile initiator as the free radical source. The peroxidation level is followed as a decrease in oxygen content of the sample [97]. The TEAC assay compares the antioxidant capacity of plasma with that of the potent antioxidant Trolox [34]. These assays give some indication of the strength of the antioxidant screen, however, these assays are only an indirect marker of the degree of oxidative stress. As with other measurements of antioxidant concentration, low TRAP or TEAC values may be due to factors other than increased utilisation of antioxidants in the presence of excess ROS.

\section{Systemic versus airway markers of lipid peroxidation}

While many of the studies of oxidative stress in asthma have used blood biomarkers (table 2), it is uncertain whether they accurately represent conditions at the airway surface, the site of oxidative damage. A recent report by Kelly et al. [43] attempted to gain a more accurate picture of local antioxidant defences in the lungs by sampling lung-lining fluid. Using BAL fluid, deficiencies in vitamins $\mathrm{C}$ and $\mathrm{E}$ and an increase in oxidised GSH levels were observed. Interestingly, these deficiencies were not reflected in plasma. Plasma vitamin $\mathrm{C}$ concentrations were similar to controls, while plasma vitamin E concentrations were elevated in asthmatics. This emphasises the importance of not relying on blood biomarkers alone to indicate airway antioxidant status and highlights the fact that the relationship between plasma and lung-lining fluid antioxidant pools is unknown. It is likely that an accurate estimate of the status of antioxidant defences requires sampling directly from the site of oxidant damage, which in asthma is the airway.

Induced sputum samples have been determined to contain a range of biomarkers useful for studying the lower respiratory tract [98] and provide a noninvasive alternative to BAL samples. Induced sputum is collected by coughing following saline inhalation. Thus, the noninvasive nature of the sample collection is advantageous compared with collection of BAL fluid, which must be performed under anaesthetic. Isoprostanes can be measured in induced sputum by EIA and levels are at least an order of magnitude higher than plasma levels [80].

Several recent studies of oxidative stress in asthma have used breath condensate samples $[12,29,38,39$, 99]. Collection of these samples is also noninvasive, however, the method is limited. Technical modifications may have overcome some of the practical problems, including elimination of ambient contamination of exhaled breath [39], but breath condensate samples are not suitable for a comprehensive analysis of oxidative stress and antioxidant defences as they rely on the volatility of the substances being measured. Thus, induced sputum samples may be the most suitable method of directly examining the spectrum of markers of oxidative stress in a variety of conditions.

\section{Therapeutic implications}

Despite the abundance of evidence indicating elevated oxidative stress and reduced antioxidant defences in asthma, antioxidant supplementation studies to date have been limited. The only longer term ( $>1$ week) supplementation trials have been encouraging, involving vitamin $C$ [100] and Se [101], both of which led to a positive improvement in asthma symptoms. However, since much of the epidemiological data suggests that whole foods (in particular fruit and vegetables) are related to asthma symptoms, it is likely that the most effective form of dietary supplementation will involve a combination of antioxidants, possibly including less well-known antioxidants (such as other flavonoids and carotenoids) that have not been considered previously in relation to asthma. This reinforces the need for a systematic and comprehensive evaluation of the antioxidant status of the asthmatic airways, to establish what combination of antioxidants will be most effective in correcting any deficiencies, thereby potentially reducing asthma incidence and severity. Evaluating the multiple and complex therapeutic combinations will be facilitated by sensitive biomarkers of oxidative stress, measured directly in the airway. Isoprostane measurement in exhaled breath condensate or induced sputum appears ideally suited to this application.

\section{Conclusion}

Oxidative stress and disturbed antioxidant status in asthmatics are well established. However, no systematic examination of lipid peroxidation and antioxidant defences in asthmatic airways exists. A comprehensive biochemical evaluation of antioxidant defences is needed to identify the nature and extent of any deficiencies. Much of the reported data has been obtained 
from various blood components, which may not be representative of what is happening at the airway surface, the initial site of oxidation. Thus, examination of airway biomarkers is critical to determine the potential for antioxidant supplementation to restore the oxidant/antioxidant imbalance. Measurement of isoprostanes in breath condensate or induced sputum should provide useful information concerning the degree of oxidant stress and success of antioxidant therapy in asthma.

\section{References}

1. Barnes PJ. Reactive oxygen species and airway inflammation. Free Rad Biol Med 1990; 9: 235-243.

2. Downs SH, Marks GB, Sporik R, Belosouva EG, Car $\mathrm{NG}$, Peat JK. Continued increase in the prevalence of asthma and atopy. Arch Dis Child 2001; 84: 20-23.

3. Fogarty A, Britton J. The role of diet in the aetiology of asthma. Clin Exp Allergy 2000; 30: 615-627.

4. Doelman CJA, Bast A. Oxygen radicals in lung pathology. Free Rad Biol Med 1990; 9: 381-400.

5. Levine SJ. Bronchial epithelial cell-cytokine interactions in airway inflammation. J Invest Med 1995; 43: 241-249.

6. Neyens HJ, Raatgeep RE, Degenhart HJ, Duiverman EJ, Kerrebijn KF. Altered leukocyte response in relation to the basic abnormality in children with asthma and bronchial hyperresponsiveness. Am Rev Respir Dis 1984; 130: 744-747.

7. Cluzel M, Damon M, Chanez P, et al. Enhanced alveolar cell luminol-dependent chemiluminescence in asthma. J Allergy Clin Immunol 1987; 80: 195-201.

8. Jarjour NN, Calhoun WJ. Enhanced production of oxygen radicals in asthma. J Lab Clin Med 1994; 123 : 131-136.

9. Kharitonov SA, Yates D, Robbins RA, LoganSinclair R, Shinebourne EA, Barnes PJ. Increased nitric oxide in exhaled air of asthmatic patients. Lancet 1994; 343: 133-135.

10. Radi R, Beckman J, Bush K, Freeman B. Peroxynitriteinduced membrane lipid peroxidation: The cytotoxic potential of superoxide and nitric oxide. Arch Biochem Biophys 1991; 288: 481-487.

11. Wu W, Chen Y, Hazen SL. Eosinophil peroxidase nitrates protein tyrosyl residues. Implications for oxidative damage by nitrating intermediates in eosinophilic inflammatory disorders. J Biol Chem 1999; 274: 25933-25944.

12. Hanazawa T, Kharitonov SA, Barnes PJ. Increased nitrotyrosine in exhaled breath condensate of patients with asthma. Am J Respir Crit Care Med 2000; 162: 1273-1276.

13. Rhoden KJ, Barnes PJ. Effect of hydrogen peroxide on guinea-pig tracheal muscle in vitro: role of cyclooxygenase and airway epithelium. $\mathrm{Br} J$ Pharmacol 1989; 98: 325-330.

14. Katsumata U, Miura M, Ichinose M, et al. Oxygen radicals produce airway constriction and hyperresponsiveness in anesthetized cats. Am Rev Respir Dis 1990; 141: 1158-1161.

15. Weiss EB, Bellino JR. Leukotriene-associated toxic oxygen metabolites induces airway hyperreactivity. Chest 1986; 89: 709-716.

16. Adler KB, Holden-Stauffer WJ, Repine JE. Oxygen metabolites stimulate release of high-molecular weight glycoconjugates by cell and organ cultures of rodent respiratory epithelium via arachidonic acid dependent mechanism. J Clin Invest. 1990; 85: 75-85.

17. Phipps RJ, Denas SM, Sielczak MV, Wanner A. The effect of $0.5 \mathrm{ppm}$ ozone on glycoprotein secretion, ion and water fluxes in sheep trachea. J Appl Physiol 1986; 60: 918-927.

18. Doelman CJA, Leurs R, Oosterom WC, Bast A. Mineral dust exposure and free radical-mediated lung damage. Exp Lung Res 1990; 16: 41-55.

19. del Maestro RF, Bjork J, Arfors K. Increase in microvascular permeability induced by enzymatically generated free radicals. I. In vivo study. Microvasc Res 1981; 22: 239-254.

20. Tate RM, van Benthuysen KM, Shasby DM, McMurtry IF, Repine JE. Oxygen-radical-mediated permability edema and vasoconstriction in isolated perfused rabbit lungs. Am Rev Respir Dis 1982; 126 : 802-806.

21. Biagioli MC, Kaul P, Singh I, Turner RB. The role of oxidative stress in rhinovirus induced elaboration of IL-8 by respiratory epithelial cells. Free Rad Biol Med 1999; 26: $454-462$.

22. Kawikova I, Barnes PJ, Takahashi T, Tadjkarimi S, Yacoub MH, Belvisi MG. 8-epi-PGF2alpha, a novel noncyclooxygenase-derived prostaglandin, constricts airways in vitro. Am J Respir Crit Care Med 1996; 153 : 590-596.

23. Fukunaga M, Takahashi K, Badr KF. Vascular smooth muscle actions and receptor interactions of 8-iso-prostaglandin E2, an E2-isoprostane. Biochem Biophys Res Comm 1993; 195: 507-515.

24. Held HD, Uhlig S. Mechanisms of endotoxin-induced airway and pulmonary vascular hypperreactivity in mice. Am J Respir Crit Care Med 2000; 162: 15471552.

25. Okazawa A, Kawikova I, Cui Z, Skoogh B, Lotvall J. 8-epi-PGF2alpha induces airflow obstruction and airway plasma exudation in vivo. Am J Respir Crit Care Med 1997; 155: 436-441.

26. Kromer BM, Tippins JR. Coronary artery constriction by the isoprostane 8-epi-prostaglandin F2alpha. Br J Pharmacol 1996; 119: 1276-1280.

27. Mobert J, Becker BF, Zahler S, Gerlach E. Hemodynamic effects of isoprostanes (8-iso-prostaglandin F2alpha and E2) in isolated guinea pig hearts. J Cardiovasc Pharmacol 1997; 29: 789-794.

28. Wood LG, Fitzgerald DA, Gibson PG, Cooper DM, Garg ML. Lipid peroxidation as determined by plasma isoprostanes is related to disease severity in mild asthma. Lipids 2000; 35: 967-974.

29. Montuschi P, Corradi M, Ciabattoni G, Nightingale J, Kharitonov SA, Barnes PJ. Increased 8-isoprostane, a marker of oxidative stress, in exhaled condensation in asthma patients. Am J Respir Crit Care Med 1999; 160: 216-220.

30. Dworski R, Murray JJ, Roberts LJI, et al. Allergeninduced synthesis of F2-isoprostanes in atopic asthmatics. Am J Respir Crit Care Med 1999; 160: 19471951.

31. Takahashi K, Nammour TM, Fukunaga M, Ebert JD, Morrow JD, Roberts LJ. Glomerular actions of a free radical generated novel prostaglandin, 8-epi-PGF $2 \alpha$, in the rat. Evidence for interactions with thromboxane A2 receptors. J Clin Invest 1992; 90: 136-141.

32. Fukunaga M, Yura T, Grygorczyk R, Badr KF. 
Evidence for the distinct nature of F2-isoprostane receptors from those of thromboxane A2. Am J Physiol 1997; 272: F477-F483.

33. Quaggiotto P, Garg ML. Isoprostanes: indicators of oxidative stress in vivo and their biological activity. In: Basu TK, Norman T, Garg ML, eds. Antioxidants in Human Health and Diseases. Oxford, CAB International, 1999; pp. 393-410.

34. Rahman I, Morrison D, Donaldson K, MacNee W. Systemic oxidative stress in asthma, COPD and smokers. Am J Respir Crit Care Med 1996; 154: 1055-1060.

35. Kalayci O, Besler T, Kilinc K, Sekerel BE, Saraclar Y. Serum levels of antioxidant vitamins (alpha tocopherol, beta carotene, and ascorbic acid) in children with bronchial asthma. Turkish J Pediatr 2000; 42: 17 21.

36. Shanmugasundaram KR, Kumar SS, Rajajee S. Excessive free radical generation in the blood of children suffering from asthma. Clinica Chimica Acta 2001; 305: 107-114.

37. Ozarus R, Tahan V, Turkmen S, et al. Changes in malondialdehyde levels in bronchoalveolar fluid and serum by the treatment of asthma with inhaled steroid and beta2-agonist. Respirology 2000; 5: 289-292.

38. Antczak A, Nowak D, Shariati B, Krol M, Piasecka $G$, Kurmanowska Z. Increased hydrogen peroxide and thiobarbituric acid-reactive products in expired breath condensate of asthmatic patients. Eur Respir $J$ 1997; 10: 1235-1241.

39. Paredi P, Kharitonov SA, Barnes PJ. Elevation of exhaled ethane concentration in asthma. Am J Respir Crit Care Med 2000; 162: 1450-1454.

40. Olopade CO, Zakkar M, Swedler WI, Rubinstein I. Exhaled pentane levels in acute asthma. Chest 1997; 111: 862-865.

41. Aderele WI, Ette SI, Oduwole O, Ikpeme SJ. Plasma vitamin $\mathrm{C}$ (ascorbic acid) levels in asthmatic children. Afr J Med Sci 1985; 14: 115-120.

42. Vural H, Uzun K. Serum and red blood cell antioxidant status in patients with bronchial asthma. Can Respir J 2000; 7: 476-480.

43. Kelly FJ, Mudway I, Blomberg A, Frew A, Sandstrom T. Altered lung antioxidant status in patients with mild asthma. Lancet 1999; 354: 482-483.

44. Mohan IK, Das UN. Oxidant stress, antioxidants, nitric oxide and essential fatty acids in bronchial asthma. Med Sci Res 1997; 25: 307-309.

45. Smith LJ, Houston M, Anderson J. Increased levels of glutathione in bronchoalveolar lavage fluid from patients with asthma. Am Rev Respir Dis 1993; 147: 1461-1464.

46. Kurosawa M, Kobayashi H, Nakano M. Cu-Zn superoxide dismutase activities in platelets from stable bronchial asthmatic patients. Int Arch Allergy Immunol 1993; 101: 61-65.

47. DeRaeve HR, Thunnissen FBMJ, Kaneko FT, et al. Decreased $\mathrm{Cu}, \mathrm{Zn}$-SOD activity in asthmatic airway epithelium: Correction by inhaled corticosteroid in vivo. Am J Physiol 1997; 272: L148-L154.

48. Smith LJ, Shamsuddin M, Sporn PHS, Denenberg M, Anderson J. Reduced superoxide dismutase in lung cells of patients with asthma. Free Rad Biol Med 1997; 22: 1301-1307.

49. Fenech AG, Ellul-Micallef R. Selenium, glutathione peroxidase and superoxide dismutase in Maltese asthmatic patients: effect of glucocorticoid administration. Pulm Pharmacol Ther 1998; 11: 301-308.
50. Comhair SAA, Bhathena PR, Dweik RA, Kavuru M, Erzurum SC. Rapid loss of superoxide dismutase activity during antigen-induced asthmatic response. Lancet 2000; 355: 624.

51. Tekin D, Ayse Sin B, Mungan D, Misirligil Z, Yavuzer S. The antioxidant defense in asthma. J Asthma 2000; 37: 59-63.

52. Novak Z, Nemeth I, Gyurkovits K, Varga SI, Matkovics B. Examination of the role of oxygen free radicals in bronchial asthma in childhood. Clinica Chimica Acta 1991; 201: 247-252.

53. Powell CVE, Nash AA, Powers HJ, Primhak RA. Antioxidant status in asthma. Pediatr Pulmonol 1994; 18: $34-38$.

54. Vural H, Uzun K, Uz E, Kocyigit A, Cigli A, Akyol O. Concentrations of copper, zinc and various elements in serum of patients with bronchial asthma. J Trace Elements Med Biol 2000; 14: 88-91.

55. Goldey DH, Mansmann HC, Rasmussen AI. Zinc status of asthmatic, prednisone-treated asthmatic, and non-asthmatic children. J Am Dietetic Assoc 1984; 84: 157-163.

56. Bibi H, Schlesinger M, Tabachnik E, Schwartz Y, Iscovitz H, Iaina A. Erythrocyte glutathione peroxidase activity in asthmatic children. Ann Allergy 1988; 61: 339-340.

57. Flatt A, Pearce N, Thomson CD, Sears M, Robinson MF, Beasley R. Reduced selenium in asthmatic subjects in New Zealand. Thorax 1990; 45: 95-99.

58. Hasselmark L, Malmgren R, Unge G, Zetterstrom O. Lowered platelet glutathione peroxidase activity in patients with intrinsic asthma. Allergy 1990; 45: 523-527.

59. Pearson DJ, Suarez-Mendez VJ, Day JP, Miller PF. Selenium status in relation to reduced glutathione peroxidase activity in aspirin-sensitive asthma. Clin Exp Allergy 1991; 21: 203-208.

60. Misso NLA, Powers KA, Gillon RL, Stewart GA, Thompson PJ. Reduced platelet glutathione peroxidase activity and serum selenium concentration in atopic asthmatic patients. Clin Exp Allergy 1996; 26: 838-847.

61. Kadrabova J, Madaric A, Kovakicova Z, Podivinsky F, Ginter E, Gazdik F. Selenium status is decreased in patients with intrinsic asthma. Biol Trace Element Res 1996; 52: 241-248.

62. Stone J, Hinks LJ, Beasley R, Holgate ST, Clayton BA. Reduced selenium status of patients with asthma. Clin Sci 1989; 77: 495-500.

63. Dauletbaev N, Rickmann J, Viel K, Buhl R, Wagner T-O-F, Bargon J. Glutathione in induced sputum of healthy individuals and patients with asthma. Thorax 2001; 56: 13-18.

64. Toth KM, Berger EM, Beehler CJ, Repine JE. Erythrocytes from cigarette smokers contain more glutathione and catalase and protect endothelial cells from hydrogen peroxide than do erythrocytes from nonsmokers. Am Rev Respir Dis 1986; 134: 281-284.

65. Borm PJ, Bast A, Wouters EF, Slangen JJ, Swaen GM, Border DE. Red blood cell antioxidant parameters in healthy elderly control subjects versus silicosis patients. Free Rad Res Comm 1987; 3: 117-127.

66. Horvath I, Donnelly LE, Kiss A, Paredi P, Kharitonov SA, Barnes PJ. Raised levels of exhaled carbon monoxide are associated with an increased expression of heme oxygenase-1 in airway macrophages in asthma: a new marker of oxidative stress. Thorax 1998; 53: 668-672. 
67. Alving K, Weitzberg E, Lundberg JM. Increased amount of nitric oxide in exhaled air of asthmatics. Eur Respir J 1993; 6: 1368-1370.

68. Wood LG, Fitzgerald DA, Gibson PG, Cooper DM, Collins CE, Garg ML. Oxidative stress in cystic fibrosis: dietary and metabolic factors. $J \mathrm{Am}$ Coll Nutr 2001; 20: Suppl. 2, 157-165.

69. Montuschi P, Paredi P, Corradi M. 8-isoprostane, a biomarker of oxidative stress is increased in cystic fibrosis. Am J Respir Crit Care Med 1999; 159: A271.

70. Montuschi P, Ciabattoni G, Paredi P, et al. 8isoprostane as a biomarker of oxidative stress in interstitial lung diseases. Am J Respir Crit Care Med 1998; 158: 1524-1527.

71. Montuschi P, Collins JV, Ciabattoni G, et al. Exhaled 8 -isoprostane as an in vivo biomarker of lung oxidative stress in patients with COPD and healthy smokers. Am J Respir Crit Care Med 2000; 162: 1175-1177.

72. Pratico D, Basili S, Vieri M, Cordova C, Violi F, Fitzgerald GA. Chronic obstructive pulmonary disease is associated with an increase in urinary levels of isoprostane F2a III, an index of oxidant stress. Am J Respir Crit Care Med 1998; 158: 1709-1714.

73. Awad JA, Roberts LJ 2nd, Burk RF, Morrow JD. Isoprostanes-prostaglandin-like compounds formed in vivo independently of cyclooxygenase: use as clinical indicators of oxidant damage. Gastroenterol Clin N Am 1996; 25: 409-427.

74. Morrow JD, Hill KE, Burk RF, Nammour TM, Badr KF, Roberts LJ. A series of prostaglandin F2-like compounds are produced in vivo in humans by a noncyclooxygenase, free radical-catalysed mechanism. Proc Natl Acad Sci USA 1990; 87: 9383-9387.

75. Awad JA, Morrow JD. Excretion of F2-isoprostanes in bile: A novel index of hepatic lipid peroxidation. Hepatology 1995; 22: 962-968.

76. Awad JA, Horn J-L, Roberts LJ, Franks JJ. Demonstration of halothane-induced hepatic lipid peroxidation in rats by quantification of F2-isoprotanes. Anesthesiology 1996; 84: 910-916.

77. Morrow JD, Roberts LJ 2nd. The isoprostanes. Current knowledge and directions for future research. Biochem Pharmacol 1996; 51: 1-9.

78. Morrow JD, Frei B, Longmire AW, et al. Increase in circulating products of lipid peroxidation (F2-isoprostanes) in smokers. N Engl J Med 1995; 332: 1198-1203.

79. Collins CE, Quaggiotto P, Wood L, O'Loughlin EV, Henry RL, Garg ML. Elevated plasma levels of F2alpha isoprostane in cystic fibrosis. Lipids 1999; 34: 551-556.

80. Wood LG, Fitzgerald DA, Gibson PG, Cooper DM, Garg ML. Increased plasma fatty acid concentration following respiratory exacerbations in cystic fibrosis is associated with elevated oxidative stress. Am J Clin Nutr 2002; 75: 668-675.

81. Roberts LJ 2nd, Morrow JD. The generation and actions of isoprostanes. Biochim Biophys Acta 1997; 1345: 121-135.

82. Gopaul NK, Zacharowski K, Halliwell B, Anggard EE. Evaluation of the postprandial effects of a fastfood meal on human plasma F2-isoprostane levels. Free Rad Biol Med 2000; 28: 806-814.

83. Richelle M, Turini ME, Guidoux R, Tavazzi I, Mefairon S, Fay LB. Urinary isoprostane excretion is not confounded by the lipid content of the diet. FEBS Letters 1999; 459: 259-262.
84. Klein T, Reutter F, Schweer H, Nusing RM. Generation of the isoprostane 8-epi-prostaglandin F2 alpha in vitro and in vivo via the cyclooxygenases. $J$ Pharmacol Exp Ther 1997; 282: 1658-1665.

85. Pratico D, Fitzgerald GA. Generation of 8epiprostaglandin F2alpha by human monocytes. Discriminate production by reactive oxygen species and prostaglandin endoperoxide synthase-2. J Biol Chem 1996; 271: 8919-8924.

86. Pratico D, Lawson JA, Fitzgerald GA. Cyclooxygenase dependent formation of the isoprostane, 8-epi prostaglandin F2alpha. J Biol Chem 1995; 270: 9800-9808.

87. Halliwell B, Grootveld M. The measurement of free radical reactions in humans. FEBS Letters 1987; 213: 9-14.

88. Pincemail J, Defraigne JO, Limet R. Oxidative stress in clinical situations - fact or fiction? Eur J Anaesthesiol 1996; 13: 219-234.

89. Brown RK, Kelly FJ. Evidence for increased oxidative damage in patients with cystic fibrosis. Pediatr Res 1994; 36: 487-493.

90. Tatum VL, Changchit C, Chow CK. Measurement of malondialdehyde by high performance liquid chromatography with fluorescence detection. Lipids 1990; 25: 226-229.

91. Gutteridge JMC, Halliwell B. The measurement and mechanism of lipid peroxidation in biological systems. TIBS 1990; 15: 129-135.

92. Esterbauer H, Striegl G, Puhl H, Rotheneder M. Continuous monitoring of in vitro oxidation of human low density lipoprotein. Free Rad Res Comm 1989; 6: $67-75$.

93. Tatzber F, Wonisch W, Schmidl E, Esterbauer H. Quantitative determination oLAb titers in various animal species. Biofactors 1997; 6: 125-130.

94. Holvoet P. Oxidative modification of low-density lipoproteins in atherothrombosis. Acta Cardiologica 1998; 53: 253-260.

95. Cross CE, van der Vliet A, O'Neill C, Louie S, Halliwell B. Oxidants, antioxidants, and respiratory tract lining fluids. Environ Health Perspect 1994; 102: Suppl. 10, 185-191.

96. Wayner DDM, Burton GW, Ingold KU, Locke S. Quantitative measurement of the total peroxyl radicaltrapping antioxidant capability of human blood plasma by controlled peroxidation. FEBS Letters 1985; 187: 33-37.

97. Langley SC, Brown RK, Kelly FJ. Reduced freeradical-trapping capacity and altered plasma antioxidant status in cystic fibrosis. Pediatr Res 1993; 33 : 247-250.

98. Gibson PG, Henry RL, Thomas P. Noninvasive assessment of airway inflammation in children: induced sputum, exhaled nitric oxide, and breath condensate. Eur Respir J 2000; 16: 1008-1015.

99. Horvarth I, Donnelly LE, Kiss A, et al. Combined use of exhaled hydrogen peroxide and nitric oxide in monitoring asthma. Am J Respir Crit Care Med 1998; 158: $1042-1046$.

100. Anah CO. High dose ascorbic acid in Nigerian asthmatics. Trop Geogr Med 1980; 32: 132-137.

101. Hasselmark L, Malmgren R, Zetterstrom O, Unge G. Selenium supplementation in intrinsic asthma. Allergy 1993; 48: 30-36. 